\title{
The Effect of Implicit Corrective Feedback on English Writing of International Second Language Learners
}

\author{
Hanadi Abdulrahman Khadawardi ${ }^{1}$ \\ ${ }^{1}$ English Language Institute, King Abdulaziz University, Saudi Arabia \\ Correspondence: Hanadi Abdulrahman Khadawardi, English Language Institute, King Abdulaziz University, \\ Saudi Arabia.
}

Received: November 22, 2020

Accepted: December 28, 2020

Online Published: December 29, 2020

doi: 10.5539/elt.v14n1p123

URL: https://doi.org/10.5539/elt.v14n1p123

\begin{abstract}
Debate about the value and the effect of both kinds of corrective feedback, explicit and implicit on second language writing has been prominent in recent years. Second language writing researchers investigate whether written implicit corrective feedback facilitates the acquisition of linguistic features. In contrast, L2 writing researchers generally emphasize the question of whether written corrective feedback helps student writers improve their writing texts and reduces their language errors. Understanding these differences is important because it provides guidelines for English language writing teachers on what are the best way to provide feedback for student writers. A quasi-experimental study was conducted to investigate the effects of implicit corrective feedback on the English writing of international second language learners in a UK educational context. It scrutinizes the application of teacher implicit written feedback in relation to the advancement of the writing skill of second language learners within a short-term period. A case study consisting of a small group of international students received implicit written feedback through codes representing specific types of writing errors. Participants were also interviewed to understand their views regarding teacher implicit written feedback and their reactions towards it. The results of the study revealed that teacher implicit written feedback helped correcting particular type of errors while other errors mandated the intervention of the teacher oral feedback.
\end{abstract}

Keywords: corrective feedback, second language writing, implicit/indirect feedback, explicit/direct feedback, L2, students' views

\section{Introduction}

Writing is a process which stimulates learners to think and organize their ideas and provide their thoughts composed in a composition of writing. It aims to build communication between the writer and the reader. Therefore, a writer should write correctly, organize their written texts, and reduce the number of written errors because their compositions will influence the understanding of the readers (Bitchener \& Ferris, 2012). Otherwise, readers will miscommunicate the written texts. Therefore, language teachers are responsible to help and enable learners to achieve the best level of writing.

Throughout the history of teaching and researching second language writing, there has been a continues dispute among scholars and language teachers regarding the value of corrective feedback in helping student writers learn how to write with minimum errors (Bitchener \& Ferris, 2012; Boggs, 2019). Although extensive research has been conducted to examine this issue, a lot of confusion remains regarding what sort of corrective feedback should be employed in teaching L2 writing (Ferris, 1999; Lalande, 1982; Hendrickson, 1980; Hyland \& Hyland, 2006; Kubota, 2001). Bitchener and Ferris (2012); Ferris and Robert (2001); and Boggs (2019) stated that most second language writing teachers agree that teacher feedback to students' writings is one of the essential elements of any writing course.

As a result of this controversy, many English language writing teachers are often confused about how to help their learners. Some teachers still have a tendency to provide direct and elaborate grammatical corrections to their students' compositions. On the other hand, there are L2 teachers prefer to encourage their learners to correct their writing errors via implicit feedback given by their teachers. However, there are a series of questions as to the usefulness of these two kinds of feedback. 


\section{Literature Review}

\subsection{Corrective Feedback}

Corrective written feedback is defined as the process that teachers or other students go through as a reflection on students' writing. It aims to provide error correction to develop students' writing compositions (Bitchener \& Ferris, 2012; Al Ajmi, 2015; Bitchener \& Knoch, 2010). Error treatment is necessary for L2 student writers. Several research studies (Boggs, 2019; Hadiyanto, 2019; Polio, Fleck, \& Leder, 1998) have demonstrated that providing learners with corrective feedback would help learners improve their writing skills. A study conducted by Chandler (2003) on second language learners throughout one semester found that error feedback reduces grammatical and lexical errors in students' writings over time. The same study concluded that providing L2 writers with feedback on their written errors would benefit them in a long-term basis by enabling them to self-edit their writings (Ferris, 2004). Ferris (2004) suggested that fossilization in the writing progress may happen to L2 writers, and their improvement in accuracy may not continue if they do not get corrective feedback on their writing errors. Long 1997 (Cited in Makino 1993) distinguished between error correction and error feedback. Makino (1993) defined Long's error feedback term as a kind of feedback which is not a correction in itself but aims to detect the learners' errors as well as elicit the corrections from them. Ferris (2002) and Al Ajmi, (2015) also stated that treatment of errors in a second language writing class is a reaction by the teacher that causes improvement in students' writings.

\subsection{Implicit and Explicit Feedback}

In this regards, Bitchener and Ferris (2012); Ferris (1995); and Lalande (1982) distinguished between two types of feedback: direct and indirect feedback. Direct or explicit feedback refers to the teacher's providing of the actual corrections of the students' errors. It is defined as the provision of the correct linguistic form or structure by the teacher to the student above or near the linguistic error. It includes the crossing out of an unnecessary sentences, word, phrase or morpheme or the insertion of a missing ones. Additional forms of direct feedback may include written a concise meta-linguistic explanation (the provision of grammar rules and examples at the end of a student's script with a reference back to places in the text where the error has occurred) and/or oral meta-linguistic explanation (a mini lesson where the rules and examples are explained, practiced, and discussed between students and teacher) (Bitchener \& Ferris, 2012). On the other hand, indirect or implicit feedback, alternatively, signifies the articulation of the type of the error, sometimes using specific codes, so that the students themselves become eager to brainstorm, search and correct the error (Ferris \& Roberts, 2001). This may be provided in one of four ways: underlining or circling the error, recording in the margin the number of errors in a given line, or using a code to show where the error has occurred and what type of error it is (Baleghizadeh \& Dadashi, 2011; Bitchener \& Knoch, 2010; Ferris \& Roberts, 2001; Robb, Ross, \& Shortreed, 1986). Although extensive research has been carried out on the kinds and the different ways of giving corrective feedback, the findings are controversial and still there is no general agreement about the best sort of corrective feedback that would enable learners to write effectively.

Indirect or implicit feedback received added support among several researchers. Ferris (2004) suggested that teachers should provide implicit feedback to engage students in cognitive problem-solving tasks and self-editing. implicit feedback also instructs learners to analyze their errors as well as find the corrections (Ferris 2002). Various studies examined the effect of two types of feedback; implicit and explicit and found that indirect feedback would help students' language accuracy over time more than direct feedback does (Mujtaba, Parkash, \& Nawaz, 2020; Baleghizadeh \& Dadashi, 2011; Hosseiny, 2014; Ferris \& Helt, 2000). Moreover, Lalande (1982) examined the writing development of intermediate level college learners studying German in light of using different feedback techniques. Lalande found that both treatment groups, direct versus implicit feedback, improved in accuracy over time but the implicit group obtained more benefits than the direct one. Lalande also suggested that implicit feedback may be more beneficial to students than direct feedback in editing, for indirect feedback can guide learning and help students solve problems by themselves (ibid). Mojtaba and Ghandi (2012) investigated the impact of indirect feedback on promoting Iranian high school students' English spelling accuracy and found that implicit feedback was more effective in improving students' composition over time than explicit feedback. Hadiyanto (2019) found that using computer-mediated corrective feedback consisting of short comments and symbols enabled students have better achievement in writing descriptive texts than those who received traditional explicit feedback. Also, Kubota (2001) has investigated the effectiveness of using the coded system on low-intermediate Japanese college students by comparing the participants' two drafts, before and after receiving the feedback. Kubota found that particular types of students' errors have decreased.

Ferris (2002) investigated the implication of the two types of implicit feedback: coded feedback where the type 
of error is pointed out and un-coded feedback where only the location of errors is identified by circling, underlining, or highlighting them. Ferris and Roberts (2001) concluded that no considerable difference is detected when using coded or un-coded indirect feedback in relation to the level of improvement of the learners' writing skill. Ferris (2002) has distinguished between two varying errors; treatable errors which students are able to solve using a grammar book and those include the common errors of verb tense agreement, article usage, plural, punctuation, capitalization, and spelling; untreatable errors, such as word choice, word order and missing or unnecessary words in which the learners need specific knowledge of the language to be able to correct them.

The one study that dealt with the effects of various kinds of teacher feedback on accuracy of both revision and subsequent writing, Ferris et al. (2000), who claimed that direct correction of error by the teacher led to more correct revisions (88\%) than implicit feedback (77\%). This study has not been published, but Ferris (2002, p. 20) discussed the findings: "However, over the course of the semester, students who received primarily indirect feedback reduced their error frequency ratios substantially more than the students who received mostly direct feedback." This 2000 study was, however, descriptive rather than quasi-experimental.

The debate between giving explicit and implicit corrective feedback on students' writing to promote their ability and accuracy is still in progress. The dilemma that might be caused by the controversial researchers that published over the last 20 years baffled teachers about giving explicit or implicit corrective feedback. Thus, research is still needed to fill in the gap and to identify specific types of corrective feedback that would enable student writers to write more efficiently and reduce their writing errors.

\subsection{Students' Perceptions towards Implicit Corrective Feedback}

Regarding the students' views about teacher written feedback, second language student writers consider this kind of feedback as an essential segment that they expect from their teacher to develop their writing ability (Ferris, 2002). Hyland and Hyland (2006) stated that second language learners have positive opinions about teacher written feedback, and they look for comments and correction on all aspects of their writing. Also, according to different surveys, (Bitchener and Ferris, 2012), and Leki, 1991; Saito, Zhang, 1995 (cited in Hyland and Hyland, 2006), found that students value teacher written feedback on their writing more than oral feedback or peer feedback. A study conducted by Ferris (2002) concluded that students prefer implicit feedback with error codes or symbols attached to their writing rather than direct teacher correction. Furthermore, according to Lee (2005) and Lalande (1982), most second language writing specialists stated that implicit teacher feedback is preferable for most students since it involves them in the correction process. Kubota (2001) interviewed a group of students, who has received a feedback and corrected the errors and found that students preferred teacher's codes to provide feedback and agreed on their effectiveness in self-correction. However, the generalizability of much published research on this issue is problematic, as the views of students may differ according to the learning context, participants' characteristics such as age and the level of L2 proficiency. Thus, current study was conducted to investigate the effect of specific type of corrective feedback, namely implicit on improving adult L2 international students' compositions.

\section{Method}

\subsection{Research Questions}

Drawing upon the previous research studies' findings on corrective feedback above mentioned and its implicitness factors in L2 writing, the current qualitative study seeks to address this issue in a concise research on a particular research group in a specific context. In doing so, the following research questions were formulated:

1) Does implicit written feedback improve $L 2$ international learners' writings?

2) Does implicit written feedback help learners correct all kinds of errors?

3) What are the adult international learners' views about using implicit written corrective feedback? Is it helpful to correct all types of errors?

\subsection{Participants}

The study was conducted on six international students, two Chinese, one Korean, and three Saudis who were enrolled in English Language Course at the Centre for Language Study at the University of Southampton, UK. It was their first semester in the academic year, at the university and after studying English for one academic year they would join their assigned departments to continue their education. All the students who participated in this study were in intermediate level, according to a pre-test, conducted by the English Centre that consisted writing a composition at the early beginning of the course. 
The ethical issues of the current study have received fair consideration. Prior to collecting the main study data, ethical procedures were approved by the Research Governance Office (RGO). The participants' permission was sought to carry out the study. When they agreed to do so, they were provided with formal information about the researcher with a clear introduction about the research, and a brief explanation of its purpose. A consent form was also given to the participants for them to sign and confirm their acceptance to participate in the study. In addition, the researcher orally informed the participants that their participation was voluntary and that they had the right to withdraw at any point. They were also informed that pseudonyms would be used when presenting their compositions and that their names would be replaced by numbers. The participants were reassured that all the data collected, even that which was recorded (interviews), would be used for the sole purpose of the study.

\subsection{Research Design}

A case study approach was chosen for the current study for several reasons. First, because it makes it possible to closely observe and collect in-depth and detailed data pertaining to a particular group (international L2 students), to explore the ways in which they react to written corrective feedback in a specific context (the UK) and their perceptions towards implicit corrective feedback. According to Lier (2011), the case study spotlights a specific group in a specific context. Thus, it relates the writing practices of the subjects to their current educational context, to offer an understanding of its influence on learners' learning processes. The case study approach therefore involves interrogating data within its actual context (Cohen et al., 2011); this makes it possible to scrutinize the actual reactions towards implicit corrective feedback of L2 learners in the UK educational sector.

A quasi-experimental design with group time series was implemented in the current research. It uses repeated drafts which enable the participants to become their own controls which reduces the effects of reactivity. A quasi-experimental time series allow for trends to be observed. It also has the potential to increase reliability (Cohen et al., 2011).

In the current study, the researcher interacts directly with the research participants, collecting their writing composition and interviewing them. As the main goal of this qualitative research is to explore the effect of implicit corrective feedback on improving students' compositions. Being a direct agent, in the current study, the researcher can effectively expand the scope of the study by recording verbal and nonverbal practices (written) and checking the accuracy of any responses with the participants themselves. According to Merriam (2009), in a qualitative approach, the researcher is the primary instrument of data collection and analysis and the direct agent as $\mathrm{s} / \mathrm{he}$ interviews, analyze or/and takes notes in a natural sitting.

Interviews can be the dominant method of data collection or may be employed alongside other methods, such as observation and document analysis. Interviews have been used widely in applied linguistics. They have been used by researchers seeking data on the stages and processes of second language acquisition, and by language examiners aiming to assess learners' language proficiency (Nunan, 2006). This method is essential in establishing the background experiences and practices of the participants and is adopted when researchers wish to understand the impressions, attitudes, feelings, motivations, perspectives, or experiences of an individual fully. It also enables evaluation and assessment of specific aspects of participants. Thus, in the current study, semi-structured interviews allowed new insights into perceptions of the participants and permitted the gathering of in-depth data about teacher implicit corrective feedback. It is a flexible method that enables respondents to speak freely about themselves (Dörnyei, 2007), so in the current study, it allowed unexpected data to emerge. Semi-structured interviews provide a great deal of flexibility, as questions can be altered in response to the direction that the conversation takes.

\subsection{Data Collection}

Two types of data were used in this study: the first set of data was based on writings of English language learners who had one week to complete them. The students were asked to write a short essay and submit their writings in the following class. The teacher checked and commented on students' writings using implicit written feedback. That is, the teacher provided feedback by using a set of codes, which students were taught at the beginning of the course, (See Appendix A for the used codes)

After receiving the coded feedback, the researcher asked the students to rewrite their texts using the teacher's codes. They found the errors indicated by theses codes and corrected some of those that they were capable to correct. The researcher collected their second drafts and compared them with their first drafts and investigated the errors categories that the students did and how they corrected them using the coded feedback. Following that, they had a session with their teacher to discuss the errors that they were unable to understand and correct. After that, the researcher asked the students to write a third draft to submit them to the researcher. The third drafts have been compared with the second drafts and scrutinized the changes that the students did after receiving the teacher 
oral feedback.

The second source of data was from an interview with the participants. They were asked using semi structured questions about their personal views in using the coded written feedback and if it is useful for them or not. Also, they were asked about their reaction whenever they receive the teacher written feedback and what the immediate step that they process. Moreover, during the interview, they had their third drafts and reflected on them regarding the types of errors that they were able to correct using the teacher written codes and the errors that they needed the teacher's explanation (oral feedback) to be corrected.

\subsection{Data Analysis}

Qualitative data analysis and coding procedure were used in the current study to analyze the data. The main content of the data was analyzed to make replicable and valid inferences from the data. Content analysis was used as it is an unobtrusive technique in that one can observe without being observed. It also can focus on language and linguistic features, meaning in context, and the rules for analysis are explicit, transparent and public (Cohen et al. 2011).

\section{Results and Discussion}

\subsection{The Results of the Comparing between the Students' Three Drafts}

This section presents the results of investigating the benefit of using teacher implicit written feedback. First of all, examining students' writings before receiving the teacher feedback demonstrated that all the learners nearly share the same sort of errors. That is, learners had verb tense agreement, wrong word, missing words, word form, incorrect expression, punctuation, capitalization and spelling errors.

Comparing the first and the second drafts of the participants revealed that after receiving the teacher implicit feedback some of their errors were corrected and their texts were much better than the first versions. For instance, student 1 , according to comment 3 , he deleted the sentence "when you sail a yacht" and changed the sentence to fit with the deletion process. Also, he deleted the preposition "for" and deleted the conjunction "and" according to comments 4 and 5. Moreover, he replaced the word "that" with "an" in the sentence "Then, every crew member should understand their responsibilities on the yacht and be tested on their sailing skill in case that emergency happens." Furthermore, he added the word "member" after the word "crew" according the comment 6. Comment 7, said that there is something missing after the word "tested", the student inserted the preposition "on" as well as changed the word form of "sail" to "sailing" (See appendix A for students' drafts).

Comparing the second draft with the third draft, the researcher could find that, the student corrected the errors that were neglected in the second draft. That is, he changed the introduction of the paragraph to more specific sentences. Also, in the following episode: "Moreover, setting off under motor power that gives you more control of your boat and prevents the collision in the narrow channels or busy harbor. In addition, do not set your sails until you travel to the open water." The students changed the whole structure of the sentence to a more organized and complete one; "Moreover, there are two instructions that each crew member should follow: setting off under motor power (which gives you more control of your boat and prevents the collision in the narrow channels or busy harbor); not setting the sails until reach open water". The students also could understand the teacher comments to delete parts of the sentence as well as change its structure. It could be concluded that, the student used the teacher oral feedback to correct the errors that he neglected in the second draft. Comparing the three drafts shows that, the students did correct some of the errors such as using prepositions, articles, and grammar using the teacher indirect codes, whereas he could not correct other errors related to sentence structure until he got the teacher oral feedback.

Student 2 was able to correct most of his errors. That is, in the first line he inserted "in order to" at the beginning of the sentence and the article "the" before "Saudi Organization" responding to comments 1 and 3. Also, he inserted the correct punctuation wherever the teacher pointed and used the capital letters for the names "Accounting" and "Management" according to comments 4, 5, 6, and 9. Moreover, he added the article "a" regarding comment 10 . The benefit of using the implicit feedback for student 2 was that it enabled him to know what his common errors that he did through his writing. For example, the researcher noticed that, the student had problem in using punctuation and capitalization. It assumed that by the end of his correction, he may know how and where to use punctuation and capitalization in the future writings.

However, through comparing the second and the third drafts, it has been found that errors that were corrected after the teacher oral feedback. For instance, the student changed the word "get" to "obtain" and changed the structure of the following sentence "Secondly, complete five required subject maters such as accounting and auditing" to "Secondly, the need to pass five required subject exams such as accounting and auditing". These 
changes demonstrate that implicit written feedback was not profitable in correcting specific kinds of errors such as word choice and sentence structure. Therefore, the student needed the teacher oral feedback to be able to understand and correct these kinds of errors. Another example of using the teacher coded feedback effectively is displayed in drafts of student 3, that is, he could correct the tense "have been decrease" to "have decreased". Moreover, the student was able to use the suitable punctuation. Moreover, he changed the expression "such as" to "for example" according to comment 6.

Comparing the second and the third drafts showed that the student corrected the errors that were not corrected in the second draft. For example, he replaced the expression "lowest developing" to "least developed". Also, in the sentence "Firstly, poverty whereas impoverished households cannot afford to enter their children in schools" he deleted "poverty whereas". He also changed the structure of the sentence "Secondly, some governments have decreased in supporting education" to "Secondly; some governments have decreased support for education". Moreover, the student changed the structure of the following two sentences "In addition, lack of entrepreneurship by the educated to share and spread knowledge. Finally, motivation whereas there are a lot of entertainments that are distracted them from learning" to a more organized and grammatical sentences "In addition, there is lack of entrepreneurship which affects spread and sharing knowledge. Finally, motivation leads to distract the educated people from learning". Through analyzing the different drafts of student 3 , it is clearly that indirect feedback enabled the student to correct some errors such as verb tense and punctuation, whereas it was not effective to enable the student to rearrange the structure of some sentences.

Also, analyzing the writings of student 5, showed that, the participant was able to replace the word "that" with "why" as well as figure out the missing word "the". Also, he deleted the article "the", and corrected the word "fee" to "fees" and the spilling of the words "majority", "result", and "education". Moreover, he corrected the verb "restrict" to "restricts" and replaced the preposition "to" with the preposition "on".

However, other errors were not corrected till the student had the session with the teacher. This is clear in the third draft, that the student corrected the errors in the sentences: "Other is that if the government arise the tuition fees, there is no obvious help to the income. For still other is that since education is the essential to the future of the country" to ". Other reason is that if the government raises the tuition fees, there is no obvious help to the income. Another reason is that since education is the essential to the future of the country". That is, he inserted the word "reason" and changed the word "arise" to "raises". Also, he changed the structure of the second sentence "for still other" to "another reason is".

The article, the plural, and the spelling errors are the most common errors student 5 did in his writing. Therefore, using the implicit feedback strategy with the students, would direct their attention to the most common errors that they make in their writing. Implicit feedback also impels them to correct these errors by themselves all over the text which results in the student being aware of these mistakes in future writing.

Generally, the result of comparing between the students' first and second drafts, indicates that implicit written feedback has positive effects on students' writing development. That is, nearly half of the errors were corrected in the second draft. Also, this kind of correction is a learning strategy in which the learner had to understand the error, look for a correction and do it by her/himself. The results of this study are in line with those of some previous studies (Mujtaba, Parkash, \& Nawaz, 2020; Hosseiny, 2014; Baleghizadeh \& Dadashi, 2011; Mojtaba and Ghandi, 2012; Hadiyanto, 2019) which reported that implicit corrective feedback on students' writing helps student learners improve their writing compositions.

However, indirect written feedback is only part of a corrective procedure, and teachers cannot completely rely on it. Comparing the three drafts showed that implicit written feedback should incorporate with the teacher oral feedback to get better results in developing students' writings. That is, analyzing the three drafts for each student and comparing between the results, demonstrate that the students were able to correct verb, articles, spelling, punctuation and capitalization errors using the teacher's codes, whereas word choice and sentence structure errors needed the teacher oral feedback to be illustrated to the students and therefore be corrected. This finding was also reported by Bitchener, Young, and Cameron (2005) in which they found a significant effect on students' writing for the combination of written and oral feedback. This also accords with a study conducted by Al Ajmi (2015) who found that corrective feedback helps students overcome their writing mistakes and improve their English writing.

The findings of the current study support the findings of "Ferris and Roberts' (2001) Error feedback in L2 writing classes How explicit does it need to be?" study, and the accompanying one, appear to agree on several points pertaining to the effectiveness of teacher implicit feedback in relation to improving the students' writing skill in L2. Participants in both studies preferred indirect feedback employing codes labelling the kinds of errors 
rather than just underling the error. Both studies, moreover, remarked how students had difficulty investing implicit feedback such as those pertaining to word choice and sentence structure, and equally appeared confident benefiting from other feedback such as those pertaining to noun endings, articles, punctuation, and word spellings. Both studies confirmed the applicability and value of teacher indirect feedback in relation to the advancement of the learners' writing skill.

\subsection{The Results of the Interview}

Regarding the third research question, students have been interviewed in order to obtain their perception of their teacher implicit feedback. The interview revealed that the students believed in the efficiency of their teacher implicit feedback. Students declared that whenever their teacher provides them with feedback pertaining to their writings' development, they become eager and motivated to look for the errors, know their types and then try to correct them. The students' reaction may be based on their motivation to master the target language as well as their awareness regarding learning the target language.

Bitchener and Ferris (2012); Leki (1990); Boggs (2019) and Kubota (2001) pointed out that students prefer error correction methods that label mistakes and hence allow the students to correct them. In the present study, likewise, students during the interview expressed their preference for the teacher's providing of implicit feedback presented in codes to categorize their errors. Students noted the advantage of such a procedure in that it would help them look for the correct answers easily and make their attention concentrated on specific kinds of rules while looking for the correct solutions. The interviewees in the current study emphasized that the teacher should use codes to refer to their errors rather than correcting them directly; such a mechanism, students argued, would enable them to brainstorm solutions to the errors and seek the correct answers which once reached tend to last in their perception; moreover, students remarked that errors that have been corrected in such a fashion rarely get repeated in the students' future writing. This finding broadly supports the work of Lee (2005) who found that around $76 \%$ of the participants prefer their teachers to provide feedback with using error codes to indicate only the kind of errors without providing direct or the correct answer.

The value of implicit written feedback in improving second language writing is exemplified in the learning experiences the interviewees provoked during the interview. Student 4, for instance, explained his better understanding of writing skill elements, such as the insertion of cautious language "may, perhaps, sometimes". as a result, to successful engagement with the teacher implicit written feedback to the student's errors. Asked how he could use the cautious expressions, the student replied, "I tried to remember what the teacher explained in last lectures and used my notes to help me use the cautious words". Student 5, moreover, was asked about his methodology of correcting noted errors about the use of articles in his writing. The student clarified, "I went to the university library and tried to get book explain articles, I found one, I cannot remember the name, I read and understand using articles". Student 1, furthermore, explained how he reverted to an English friend of his in order to understand and find solutions to writing errors noted by his teacher implicit coded feedback. Such examples demonstrate how students' interaction with implicit feedback helped improving the students' command of L2 writing not only through genuine understanding of the solution of the errors but also through the students' engaging with other language learning activities such as communication with native speakers and successful investment of the library.

The interviewees also differentiated between treatable errors, which students felt confident to solve on their own, and untreatable errors, which students needed the teacher oral feedback for a further illustration of the nature of the errors and their possible corrections; such an additional assistance become evident with errors pertaining to sentence structure and word choice. Student 6 , for instance, explained his ability independently to correct errors in relation to the use of the preposition "in" instead of "of" according to comment 2. Similarly, correcting the verb tense, the student added the verb to be "is" to the verb "designed" to get the correct tense. The student's wrong choice of the word "overview" instead of "overlook", however, required a further oral explanation from the teacher for the student to reach the correct answer. The student mentioned also that he could not understand teacher's comment 9 and needed the teacher oral feedback to understand why it was an error. Another example of untreatable errors is shown in the writing of student 3 , where he had to consult with his teacher to understand the wrong usage of the expression, "lowest developing," and the correct one, "least developed." In comments 8 and 9, moreover, the student sought his teacher oral feedback to modify the sentence: "motivation whereas there are a lot of entertainments that are distracted them from learning", to "motivation leads to distract the educated people from learning". Such examples reflect the limitation of some implicit feedback to fully guide the students' search and finding of the correct answer. In that students find themselves referring to their teachers for further assistance and oral explanation and expanded corrective feedback. 


\section{Conclusion and Implications}

The present study attempted (1) to determine whether using the teacher implicit written feedback presented in codes is beneficial for improving students' writing or not, (2) to identify the types of errors that implicit written feedback succeeded in enabling the students to correct, and (3) to determine the learners' views on using the teacher written codes to correct their writing errors.

\subsection{Research Question 1}

With respect to the first aim, it was found that the teacher implicit written feedback had a significant effect in helping students improve their writing for a short time. Students used the written codes to produce more accurate text presented in the second drafts. Such an engagement with the text appeared to enhance the students learning of L2 in that, as students 1, 4, and 5 contended during the interview, students revert to several learning activities including reading grammar books, using previous lectures and notes and consulting with native speakers in order to solve the written errors occurred in their first drafts.

\subsection{Research Question 2}

Concerning the second aim, both methods, arrived at the finding that implicit written feedback is effectual in enabling the students to correct verb tense, punctuation, capitalization, preposition and uses of articles. Errors pertaining to language issues such as sentence structure and word choice, however, needed different kind of feedback to be corrected. Regarding the latter, the study revealed that learners need the implicit written feedback accompanied with direct oral feedback to be able to understand all the errors, their causes as well as correct them. The result of the present study and the previous literature (Mujtaba, Parkash, \& Nawaz, 2020; Hosseiny, 2014; Baleghizadeh \& Dadashi, 2011; Mojtaba \& Ghandi, 2012; Hadiyanto, 2019) indicate that students learn more and make fewer errors on subsequent writing from either finding their own errors or/and making their own corrections, rather than receiving explicit corrections from the teacher. The superiority of the implicit corrective feedback may be because, not surprisingly, students are able to correct significantly more of their errors on their revisions after receiving corrective codes rather than after receiving teacher oral feedback. Perhaps the greater cognitive effort expended in making their own corrections using the teachers' codes.

\subsection{Research Question 3}

As far as the third aim is concerned, the interview brought to light the students' positive opinion and attitude towards the implicit feedback represented in codes. All the six interviewees agreed on the impact of implicit feedback upon the improvement of their writing skills. Interviewees also shared the same views that implicit written feedback is accurate to enable them to correct specific kinds of errors. Finally, analyzing the three drafts and the interview with the students led to the same results, that is implicit written feedback has a significant role in improving second language learners' writings.

Although it is impossible to generalize the findings gathered from a small sample in a single text, this study has several implications for classroom pedagogy in teaching second language writing. First of all, using more than one method to provide students with feedback should be considered. Moreover, the teacher should provide the students with rich input throughout the course in order to facilitate their writing and their self-editing using the teacher's written codes. Furthermore, choosing the proper method to provide the students with feedback should take in consideration the three factors, the students' language proficiency level, age group and their motivation to learn the target language. In the meantime, using implicit feedback followed by teacher oral feedback is an efficient strategy for teaching writing skill as well as a kind of exercise that the students need to practice correcting their writing errors.

\section{References}

Al Ajmi, S. (2015). The effect of written corrective feedback on Omani students' accuracy in the use of English prepositions. Advances in Language and Literary Studies. Australian International Academic Centre, Australia, 6(1). https://doi.org/10.7575/aiac.alls.v.6n.1p.61

Baleghizadeh, S., \& Dadashi, M. (2011). The effect of direct and indirect corrective feedback on students' spelling errors. Profile Issues in Teachers` Professional Development, 13(1), 129-137. Retrieved from https://www.researchgate.net/publication/262444891_The_Effect_of_Direct_and_Indirect_Corrective_Feed back_on_Students\%27_Spelling_Errors

Barbour, R. (2009). Introducing Qualitative Research, A Student Guide to the Craft of Doing Qualitative Research. London: SAGE Publications Ltd.

Bitchener, J., \& Ferris, D. R. (2012). Written corrective feedback in second language acquisition and writing. 
Routledge. New York. https://doi.org/10.4324/9780203832400

Bitchener, J., \& Knoch, U. (2010). Raising the linguistic accuracy level of advanced L2 writers with written corrective feedback. Journal of Second Language Writing, 19(4), 207-217. https://doi.org/10.1016/j.jslw.2010.10.002

Bitchener, J., Young, S., \& Cameron, D. (2005). The effect of different types of corrective feedback on ESL student writing. Journal of Second Language Writing, 14, 191-205. https://doi.org/10.1016/j.jslw.2005.08.001

Boggs, Jill A. (2019). Effects of teacher-scaffolded and self-scaffolded corrective feedback compared to direct corrective feedback on grammatical accuracy in English L2 writing. Journal of Second Language Writing, 46, 2019. https://doi.org/10.1016/j.jslw.2019.100671

Chandler, J. (2003). The efficacy of various kinds of error feedback for improvement in the accuracy and fluency of L2 student writing. Journal of Second Language Writing, 12, 267-296. https://doi.org/10.1016/S1060-3743(03)00038-9

Cohen, L., Manion, L., \& Morrison, K. (2011). Research Methods in Education. USA and Canada: Routledge.

Dörnyei, Z. (2007). Research Methods in Applied Linguistics: Quantitative, Qualitative, and Mixed Methodologies. China: OUP Oxford. Retrieved from https://books.google.com/books?id=gNh6QgAACAAJ\&pgis=1

Ferris, D. R. (1995). Teaching ESL composition students to become independent self-editors. TESOL Journal, $4(4), 18-22$.

Ferris, D. R. (1999). The case for grammar correction in L2 writing classes: A response to Truscott 1996. Journal of Second Language Writing, 8, 1-10. https://doi.org/10.1016/S1060-3743(99)80110-6

Ferris, D. R. (2002). Treatment of Errors in Second Language Student Writing. University of Michigan: The University of Michigan Press.

Ferris, D. R. (2004). The "grammar correction" debate in L2 writing: where are we, and where do we go from here? (and what do we do in the meantime...?). Modern Language Journal, 13, 46-62. https://doi.org/10.1016/j.jslw.2004.04.005

Ferris, D. R., \& Helt, M. (2000). Was Truscott right? new evidence on the effects of error correction in L2 writing classes. Paper presented at the American Association of Applied Linguistics Conference, Vancouver, B. C.

Ferris, D., \& Roberts, B. (2001). Error feedback in L2 writing classes, how explicit does it need to be? Journal of Second Language Writing, 10, 161-184. https://doi.org/10.1016/S1060-3743(01)00039-X

Friedman, D. A. (2012). How to Collect and Analyze Qualitative Data. In A. Mackey \& S. M. Gass, (Eds.). Research Methods in Second Language Acquisition: A Practical Guide. Oxford: Blackwell Publishing Ltd. https://doi.org/10.1002/9781444347340.ch10

Hadiyanto, S. (2019). The effect of computer-mediated corrective feedback on the students' writing. Journal of English Teaching and Learning, 8(2), 1-11. Retrieved from https://www.riset.unisma.ac.id/index.php/LANG/article/view/2881

Hendrickson, J. M. (1980). The treatment of error in written work. Modern Language Journal, 64, 216-221. https://doi.org/10.1111/j.1540-4781.1980.tb05188.x

Hosseiny, M. (2014). The role of direct and indirect written corrective feedback in improving Iranian EFL students' Writing Skill. Procedia-Social and Behavioural Sciences, 98, 668-674. https://doi.org/10.1016/j.sbspro.2014.03.466

Hyland, K., \& Hyland, F. (2006). The Efficacy of Various Kinds of Error Feedback for Improvement in the Accuracy and Fluency of L2 Student Writing. Cambridge: Cambridge University Press.

Kroll, B. (2003). Exploring the Dynamics of Second Language Writing. Cambridge: Cambridge University Press. https://doi.org/10.1017/CBO9781139524810

Kubota, M. (2001). Error correction strategies used by learners of Japanese when revising a writing task. System, 29, 467-480. https://doi.org/10.1016/S0346-251X(01)00026-4

Lalande, J. F. (1982). Reducing composition errors: an experiment. Modern Language Journal, 66, 140-149. https://doi.org/10.1111/j.1540-4781.1982.tb06973.x 
Lee, L. (2005). Error Correction in the L2 Writing Classroom: What Do Students Think? TESL Canada Journal/Revue TESL Du Canada, 22(2). https://doi.org/10.18806/tesl.v22i2.84

Lier, L. van. (2011). Case Study. In E. Hinkel, (Ed.), Handbook of Research in Second Language Teaching and Learning. New York: Routledge (pp. 998).

Makino, T. Y. (1993). Learner self-correction in EFL written compositions. ELT Journal, 47(4), $337-341$. https://doi.org/10.1093/elt/47.4.337

Mojtaba, M., \& Ghandi, M. (2012). The effect of direct and indirect corrective feedback on Iranian EFL learners' spelling errors. English Language Teaching, 7(8), 53-61. https://doi.org/10.5539/elt.v7n8p53

Mujtaba, S. M., Parkash, R., \& Nawaz, M. W. (2020). Do indirect coded corrective feedback and teachers short affective comments improve the writing performance and learners uptake? Reading \& Writing Quarterly, 36(1), 34-47. https://doi.org/10.1080/10573569.2019.1616638

Mulati, D. F., Nurkamato, J., \& Darajati, N. A. (2020). The Teachers' beliefs in teacher written corrective feedback on the students' writing. Journal of Applied Linguistics and Literature, 5(1), 1-10. https://doi.org/10.33369/joall.v5i1.7644

Nunan, D. (2006). Research Methods in Language Learning (16th ed.). United States of America: Cambridge University Press.

Polio, C., Fleck, C., \& Leder, N. (1998). If I only had more time: ESL learners' changes in linguistic accuracy on essay revisions. Journal of Second Language Writing, 7(1), 43-68. https://doi.org/10.1016/S1060-3743(98)90005-4

Tracy, S. J. (2013). Qualitative Research Methods: Collecting Evidence, Crafting Analysis, Communication Impact. USA: Library of Congress Cataloging in Publication data. 


\section{Appendix A}

Codes Used for Implicit Corrective Feedback

Symbols for Correction Code:

\begin{tabular}{|l|l|l|}
\hline Symbol & Meaning & Example \\
\hline T & Tense & $\begin{array}{l}\text { I see my friend } \\
\text { yesterday. }\end{array}$ \\
\hline V & Verb \\
\hline p.p. & Past participle & $\begin{array}{l}\text { I always make my } \\
\text { homework }\end{array}$ \\
\hline ^ & omission & $\begin{array}{l}\text { Our neighbour has took } \\
\text { our bin! }\end{array}$ \\
\hline col. & Collocation \\
\hline rep. & Repetition & I often work ^ home. \\
& Agreement & $\begin{array}{l}\text { The police officer lifted } \\
\text { his hand. } \\
\text { col. }\end{array}$ \\
\hline W/O & Word order & $\begin{array}{l}\text { The researchers } \\
\text { research information. } \\
\text { Research is important } \\
\text { for the company. rep. }\end{array}$ \\
\hline S - V & Delete & $\begin{array}{l}\text { I every year go on } \\
\text { holiday. }\end{array}$ \\
\hline
\end{tabular}




\section{Appendix B}

Samples of Students' Drafts

It is important to keep in mind that a yacht
is basically a floating island that keeps you
and your crew from the danger of drawing.
As such, it is necessary to know what you
are doing when you sail a yacht. First, you
should know about your boat, including its
engine, sails, lines and especially for its
emergency equipment. Before your
voyage, you should make sure everything
is in working order. And then, every crew
should understand their responsibilities on
the yacht and be tested their sail skill in
case that emergency happens. Moreover,
setting off under motor power that gives
you more control of your boat and prevents
the collision in the narrow channels or
busy harbor. In addition, do not set your




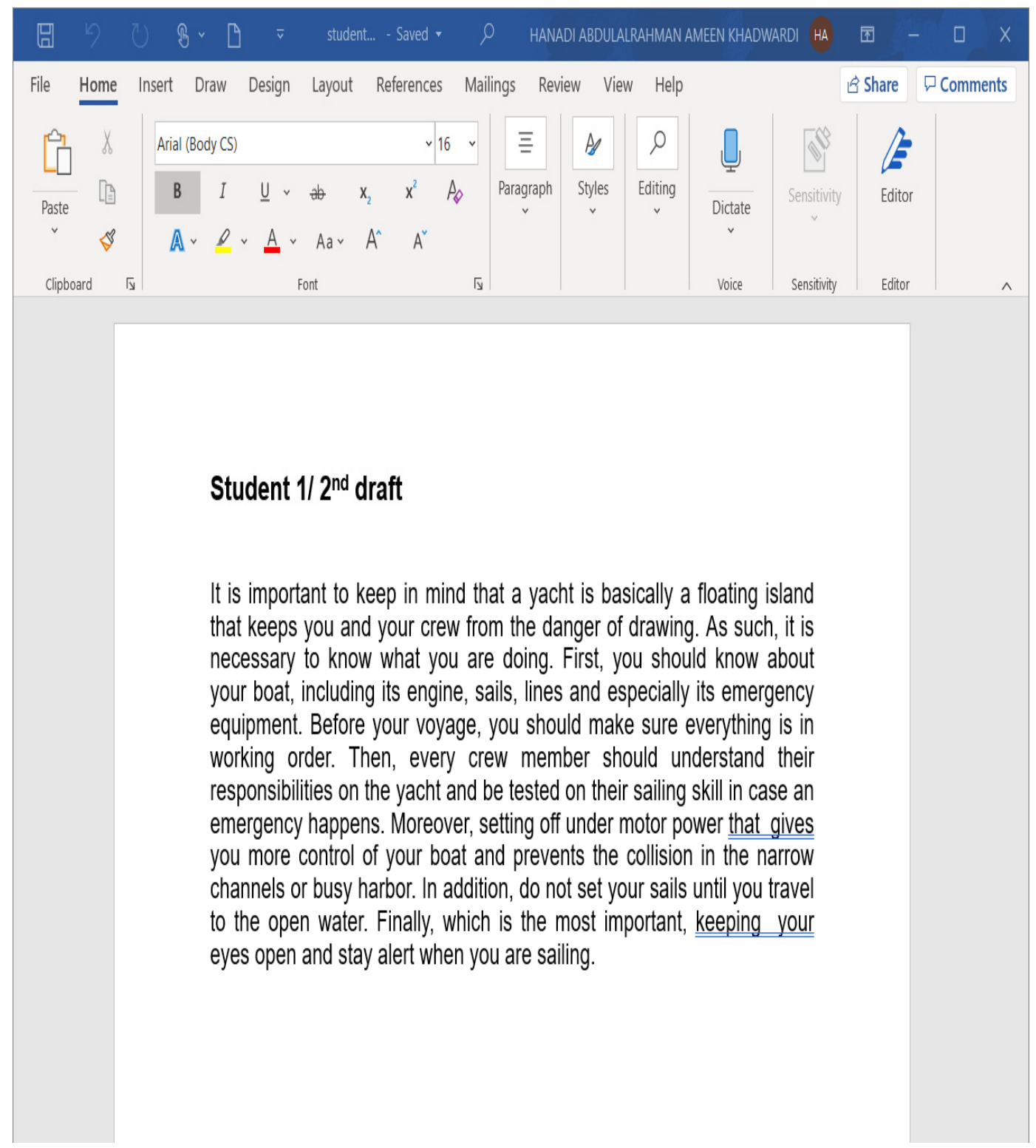




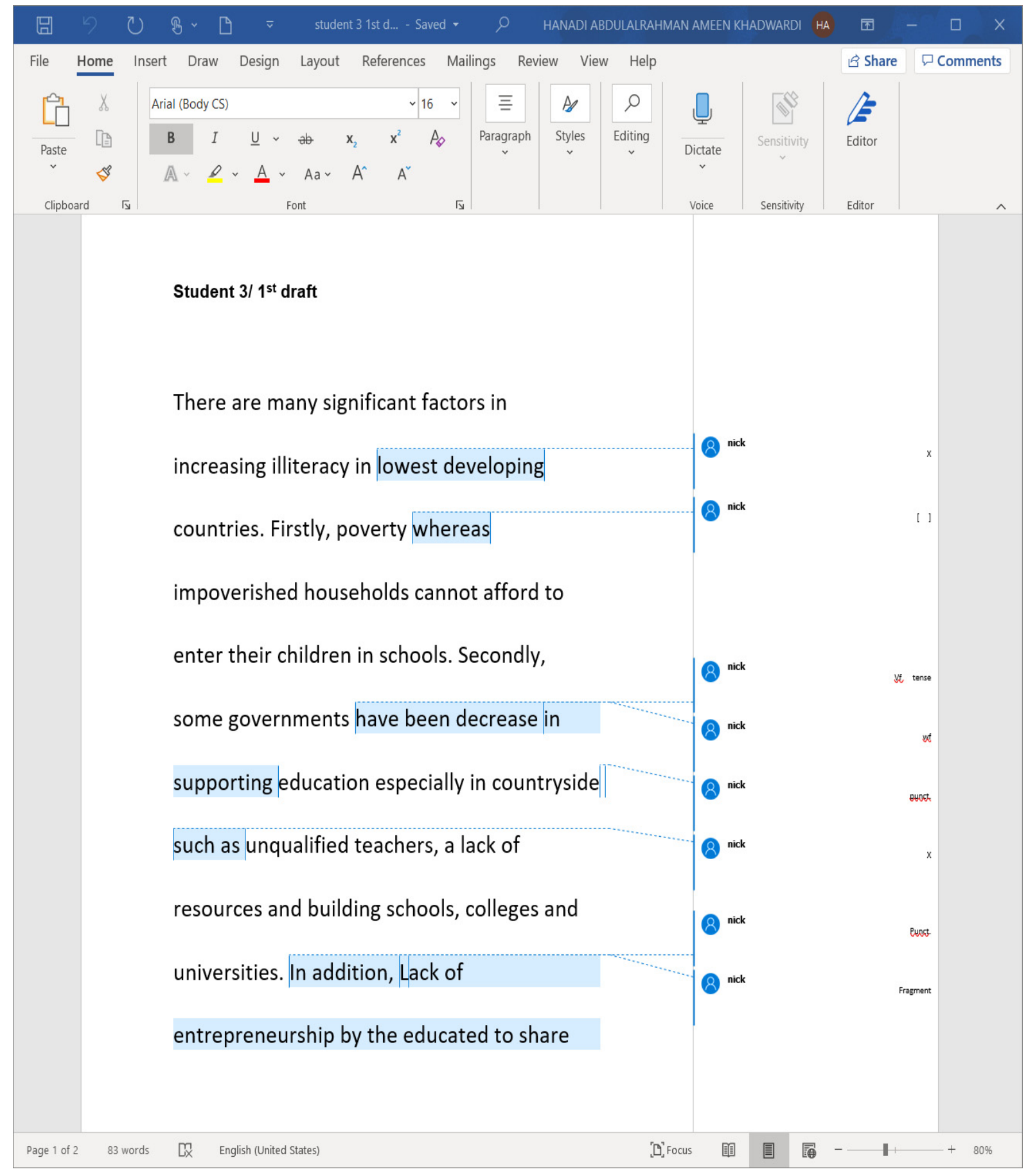




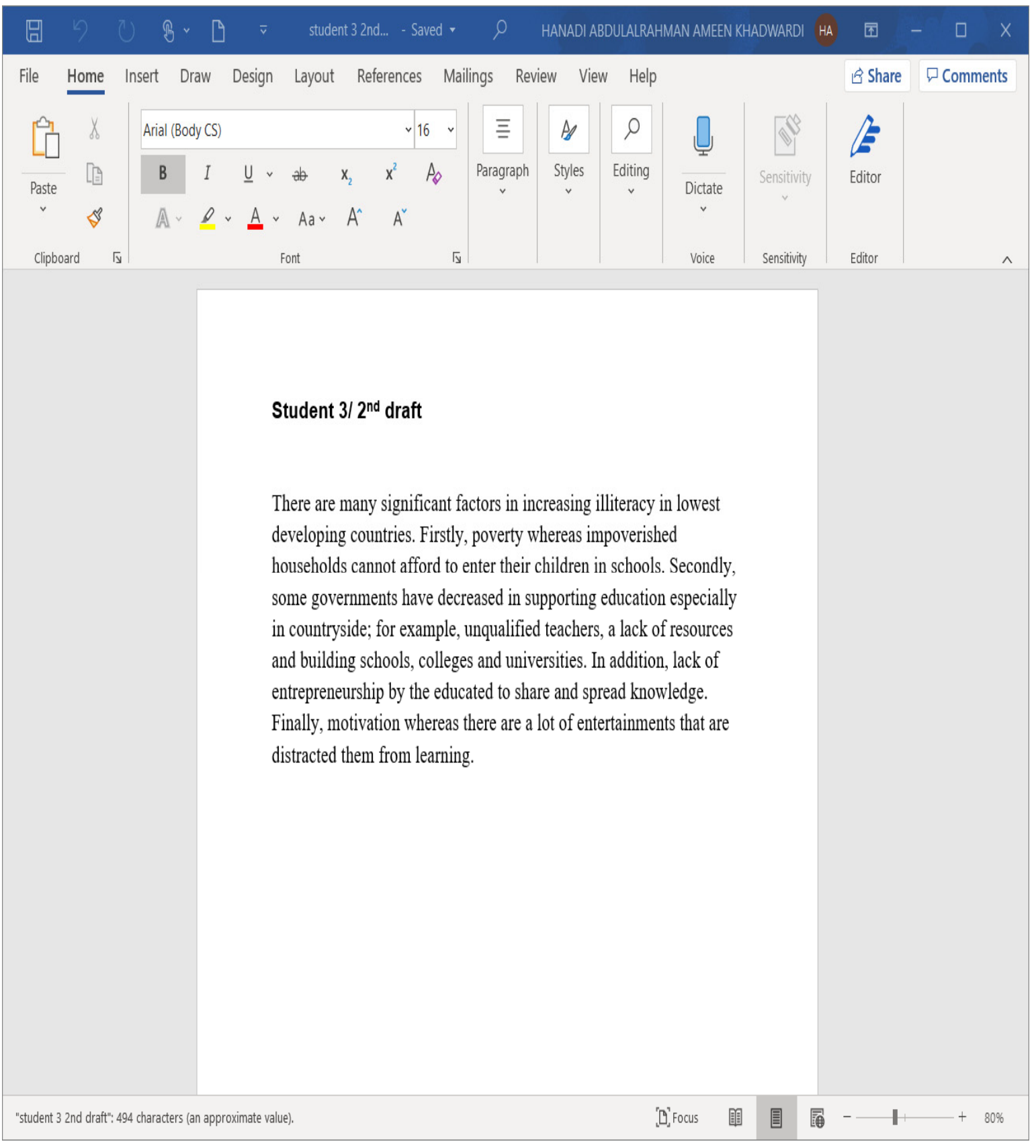




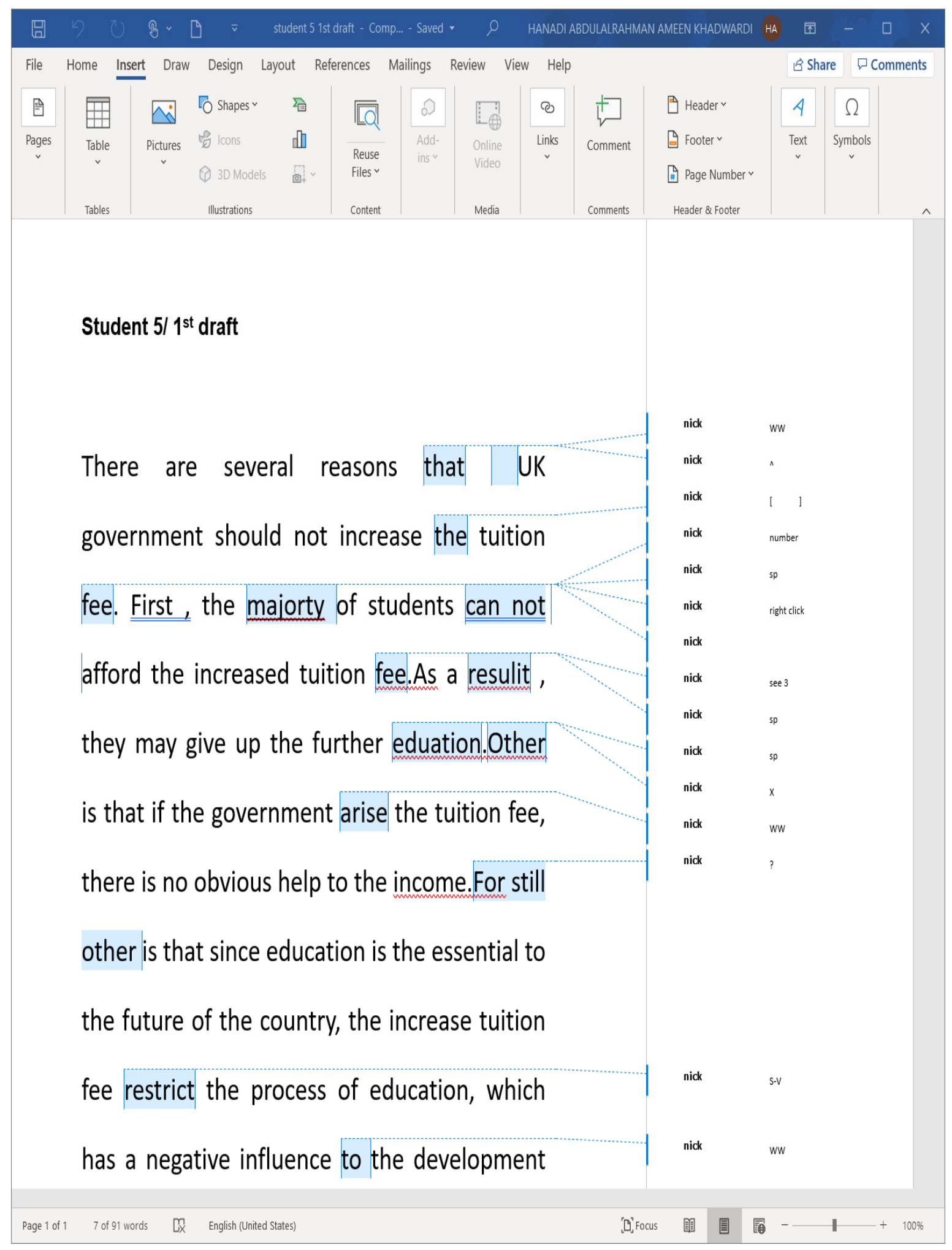




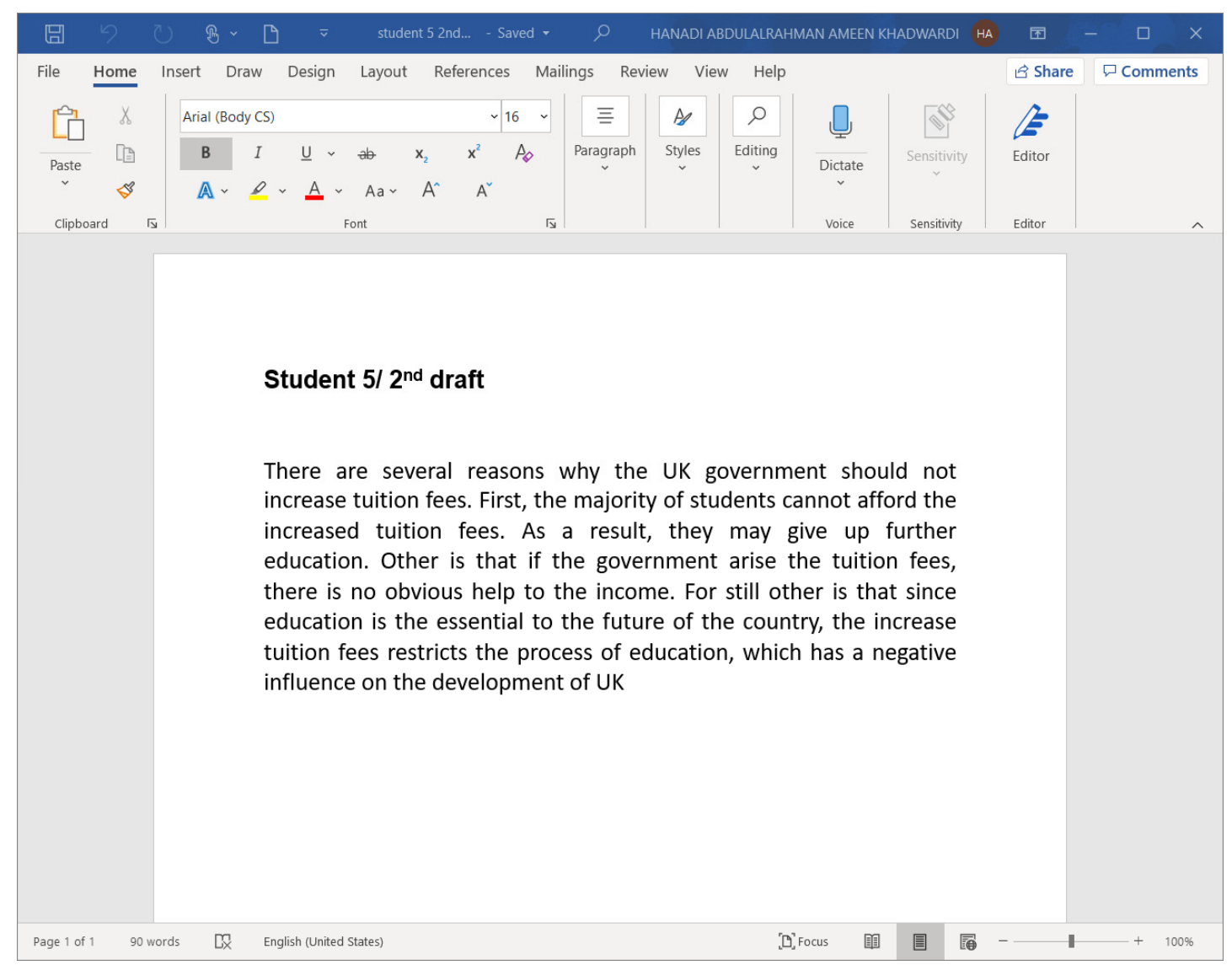

\section{Copyrights}

Copyright for this article is retained by the author(s), with first publication rights granted to the journal.

This is an open-access article distributed under the terms and conditions of the Creative Commons Attribution license (http://creativecommons.org/licenses/by/4.0/). 